\title{
Alternative Strain Aging Effect for Fatigue of Ductile Bulk Glassy Alloys
}

\author{
Yoshihiko Yokoyama $^{1}$, Markus Wilde ${ }^{2}$, Katsuyuki Fukutani ${ }^{2}$ and Akihisa Inoue ${ }^{1}$ \\ ${ }^{1}$ Advanced Research Center of Metallic Glasses, Institute for Materials Research, Tohoku University, \\ Katahira, Aobaku, Sendai 980-8577, Japan \\ ${ }^{2}$ Institute for Industrial Science, The University of Tokyo, Komaba, Meguroku, Tokyo 153-8505, Japan
}

The metal fatigue mechanism of bulk glassy alloys (BGAs) resulting from the ductile nature of a glassy alloy differs from that of the conventional crystalline engineering alloys. Extreme hardening of the fatigue crack tip on the fatigue-fractured surface of the $\mathrm{Zr}$ - and $\mathrm{Pd}-$ based BGAs was usually observed just before the final fracture. Embrittlement around the fatigue crack tip, generated by excessive hardening to stop the fatigue crack propagation, significantly decreases fatigue fracture toughness. Hardening by hydrogen was also considered as an alternative mechanism of the strain aging effect in fatigue of glassy alloys because the second phase cannot be observed on a fatigue fracture surface, and only hydrogen promotes hardening, maintaining a glass structure. Hydrogen analysis of a micro area region was attempted with nuclear reaction analysis which used accelerated ion ${ }^{15} \mathrm{~N}$ up to $6.385 \mathrm{MeV}$ to determine the hydrogen concentration of the fatigue-fracture surface. We successfully measured the characteristic enrichment of hydrogen near the fatigue-fracture surface. [doi:10.2320/matertrans.MF200614]

(Received November 29, 2006; Accepted February 26, 2007; Published May 25, 2007)

Keywords: nuclear reaction analysis, hydrogen, hardening, strain aging, fatigue, Wöhler curve

\section{Introduction}

Glassy alloys have unique features that result from their glassy random structure and flexible metallic bonds. Special traits of glassy alloys include their mechanical properties. Since the glassy alloys exhibit ductile metallic bonding and have a non-periodic structure, we can expect ${ }^{1)}$ extremely high toughness and high strength. The mechanical characteristics of BGAs are said to be especially tough. ${ }^{2)}$ They differ greatly from oxide glasses because glassy alloys can be bent ${ }^{3)}$ or rolled $^{4)}$ at room temperature, and they do not fail even if dropped. Recently, a BGA that exhibits fracture toughness equivalent to engineering steels has also been reported. ${ }^{5)}$ The high toughness of glassy alloys significantly influences fatigue features. BGAs exhibit metallic Wöhler curves and sufficient high fatigue limits. ${ }^{6-8)}$ However, embrittlement by structural relaxation $^{9,10)}$ or oxidization ${ }^{11,12)}$ cannot be completely avoided, so attention should be paid when fabricating ductile glassy alloys. Structural relaxation is almost certainly caused by expansion of the specimen due to a decreased cooling rate, so density measurement has been proposed ${ }^{13)}$ as a means to maintain the quality of glassy alloys.

The distinct fatigue limit, which is characterized by a distinct bending point on the Wöhler curve knee, is usually seen in glassy alloys. The knee on Wöhler curve implies a high resistance to fatigue, and it is also seen in such conventional ductile steels such as engineering alloys and metals. Strain aging can be considered as an origin of the knee on the Wöhler curve of steel. Work hardening by plastic deformation in front of the fatigue crack tip generates significant hardening and stops the fatigue crack propagation. Since there is no work hardening in glassy alloys, hardening mechanisms such as strain aging cannot be expected. However, hardening around a fatigue crack tip was observed in Zr- and Pd-based BGAs during fatigue testing of a glassy alloy. We proposed ${ }^{14)}$ that hardening by concentrated hydrogen is an alternative mechanism to the strain aging effect for a glassy alloy for two reasons. First, no crystallization is observed in the hardened fatigue fracture region by trans- mission electron microscope (TEM), and the hydrogen is the only element that significantly hardens a glassy alloy without any crystallization. Second, the degradation of fatigue fracture toughness comparable with fracture toughness is probably caused by excessive hardening due to concentrated hydrogen around the fatigue crack tip.

In this research, the Wöhler curve was produced by rotating beam fatigue testing using rather large rod-shaped samples with a size suitable for hydrogen analysis by nuclear reaction analysis. ${ }^{15)} \mathrm{We}$ also examined the distribution of hardness on fatigue fracture surfaces of $\mathrm{Zr}$ - and Pd-based BGAs and measured the hydrogen concentration around the fatigue-fracture surface by nuclear reaction analysis.

\section{Experimental}

Master-alloy ingots of ternary and quaternary $\mathrm{Zr}$-based alloys were prepared by arc-melting a mixture of pure $\mathrm{Zr}, \mathrm{Cu}$, $\mathrm{Ni}, \mathrm{Pd}$ and $\mathrm{Al}$ metals in an argon atmosphere. Zr-based BGAs were cast into rod-shaped specimens $8 \mathrm{~mm}$ in diameter and $60 \mathrm{~mm}$ long by the tilt casting technique. Pd-based master alloys were melted from metal elements $\mathrm{Pd}, \mathrm{Cu}, \mathrm{Ni}$ and $\mathrm{P}$, and pre-alloyed Pd-P ingot in a quartz tube by an induction heating furnace. $\mathrm{Pd}_{40} \mathrm{Cu}_{30} \mathrm{Ni}_{10} \mathrm{P}_{20}$ BGAs were fabricated by water quenching after preliminary degassing at high temperature $(1400 \mathrm{~K})$ with covered $\mathrm{B}_{2} \mathrm{O}_{3}$ flax. Hydrogen was charged by an electrolytic process with a BMG disk $(8 \mathrm{~mm}$ in diameter and $2 \mathrm{~mm}$ thick) cathode in a $1 \mathrm{~N}$ sulfuric-acid solution with a constant current density of $1.0 \mathrm{kA} / \mathrm{m}^{2}$. The mean hydrogen concentration of the BGA samples was measured by fusion using the helium gas thermal conductivity method. Ono-type rotating-beam fatigue testing machines (Shimadzu H5) were used for fatigue testing of $\mathrm{Zr}$ - and $\mathrm{Pd}-$ based bulk glassy metals in an air atmosphere at room temperature. An X-ray diffractometer was used to examine the crystalline quality and identify the different phases present in the alloys. The microstructures of fatigue-fractured samples were examined by scanning electron microscope (SEM; JEOL 5200), and the hardness of the structure was 
measured using a micro Vickers apparatus (Akashi HAV). The hydrogen concentration distribution was measured by nuclear reaction analysis using accelerated ions $\left({ }^{15} \mathrm{~N}\right.$ up to $6.385 \mathrm{MeV}$ ) with a tandem ion beam accelerator at the University of Tokyo. Resolution limits of hydrogen concentration and depth resolution are estimated about 0.1 at $\%$ and $5 \mathrm{~nm}$, respectively.

\section{Results and Discussion}

Figure 1 plots Wöhler curves of $\mathrm{Zr}_{50} \mathrm{Cu}_{40} \mathrm{Al}_{10},{ }^{16)} \mathrm{Zr}_{50^{-}}$ $\mathrm{Cu}_{30} \mathrm{Ni}_{10} \mathrm{Al}_{10},{ }^{16)} \mathrm{Zr}_{50} \mathrm{Cu}_{37} \mathrm{Al}_{10} \mathrm{Pd}_{3},{ }^{14)}$ flux-treated $\mathrm{Pd}_{40} \mathrm{Cu}_{30^{-}}$



Fig. 1 Wöhler curves of $\mathrm{Zr}_{50} \mathrm{Cu}_{40} \mathrm{Al}_{10}, \mathrm{Zr}_{50} \mathrm{Cu}_{30} \mathrm{Ni}_{10} \mathrm{Al}_{10}, \mathrm{Zr}_{50} \mathrm{Cu}_{37}$ $\mathrm{Al}_{10} \mathrm{Pd}_{3}$, flux-treated $\mathrm{Pd}_{40} \mathrm{Cu}_{30} \mathrm{Ni}_{10} \mathrm{P}_{20}$ and untreated $\mathrm{Pd}_{40} \mathrm{Cu}_{30} \mathrm{Ni}_{10} \mathrm{P}_{20}$ BGAs with an Ono-type rotating beam fatigue test machine.
$\mathrm{Ni}_{10} \mathrm{P}_{20},{ }^{17)}$ and non-flux-treated $\mathrm{Pd}_{40} \mathrm{Cu}_{30} \mathrm{Ni}_{10} \mathrm{P}_{20}{ }^{17)}$ BGAs. All of the Wöhler curves exhibit the distinct knee and fatigue limit, whereas the $\mathrm{Pd}_{40} \mathrm{Cu}_{30} \mathrm{Ni}_{10} \mathrm{P}_{20}$ BGA indicates decreased fatigue strength after the knee. Furthermore, the gradient of the Wöhler curve before the knee point of $\mathrm{Pd}_{40} \mathrm{Cu}_{30} \mathrm{Ni}_{10} \mathrm{P}_{20}$ BGA differs from those of $\mathrm{Zr}$-based BGAs. The gradient of $\mathrm{Pd}_{40} \mathrm{Cu}_{30} \mathrm{Ni}_{10} \mathrm{P}_{20}$ BGA becomes steep due to degraded purity without flux treatment before casting, whereas a much steeper gradient was seen in Zr-based BGAs. Such a significant difference in the gradients of Wöhler curves arises from the difference in the fatigue mechanism. In the ductile BGAs, the fatigue-fractured surface is characterized by striation-like marks, whose structure implies a fatigue crack propagation mechanism. However, we could not observe the striation-like marks on the fatigue-fractured surface of $\mathrm{Pd}_{40} \mathrm{Cu}_{30} \mathrm{Ni}_{10} \mathrm{P}_{20}$ BGA.

The hardness distribution of the fatigue-fractured surface was also examined to confirm the existence of strain aging effect in $\mathrm{Zr}$ - and Pd-based BGAs. Figure 2(a) depicts the fatigue-fractured surface of $\mathrm{Zr}_{50} \mathrm{Cu}_{30} \mathrm{Ni}_{10} \mathrm{Al}_{10}$ BGAs after fatigue testing $\left(\sigma_{\mathrm{a}}=570 \mathrm{MPa}\right.$ and $N_{\mathrm{f}}=5.6 \times 10^{4}$ cycles; arrow $\mathrm{A}$ in Fig. 1. Hardness distributions were measured along two directions from the fatigue crack initiation site, and micro Vickers hardnesses were measured in 10 different areas around marks from " $b$ " to " $g$ " on the fatigue-fractured surface. The fatigue-fractured surface was covered all with striation-like marks as shown in Fig. 2(b). The hardness distributions are denoted in Fig. 2(c). The hardness is maximum at the interface between the fatigued and final

(A) $\mathrm{Zr}_{50} \mathrm{Cu}_{30} \mathrm{Ni}_{10} \mathrm{Al}_{10} \quad \sigma_{\mathrm{a}}=570 \mathrm{MPa}, \mathrm{N}_{\mathrm{f}}=5.6 \times 10^{4}$
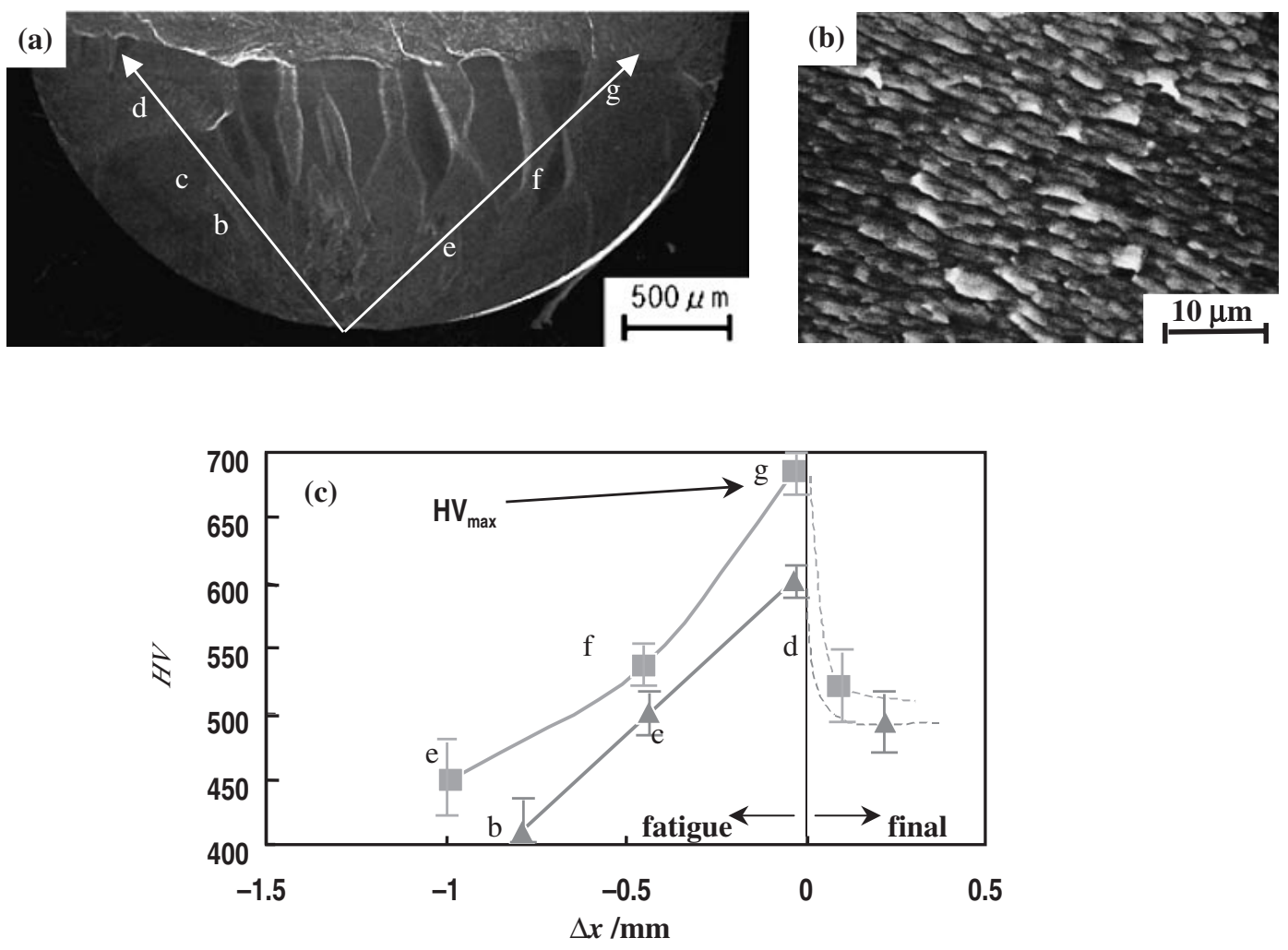

Fig. 2 SEM image of fatigue-fractured surface (a), its magnified image (b) and its hardness distributions of the fatigue-fractured surface (c) of $\mathrm{Zr}_{50} \mathrm{Cu}_{30} \mathrm{Ni}_{10} \mathrm{Al}_{10}$ BGAs after fatigue test $\left(\sigma_{\mathrm{a}}=570 \mathrm{MPa}\right.$ and $N_{\mathrm{f}}=5.6 \times 10^{4}$ cycles; arrow (A), on Fig. 1). 
(B) $\mathrm{Pd}_{40} \mathrm{Cu}_{30} \mathrm{Ni}_{10} \mathbf{P}_{20} \quad \sigma_{\mathrm{a}}=240 \mathrm{MPa}, \mathrm{N}_{\mathrm{f}}=3.3 \times 10^{8}$

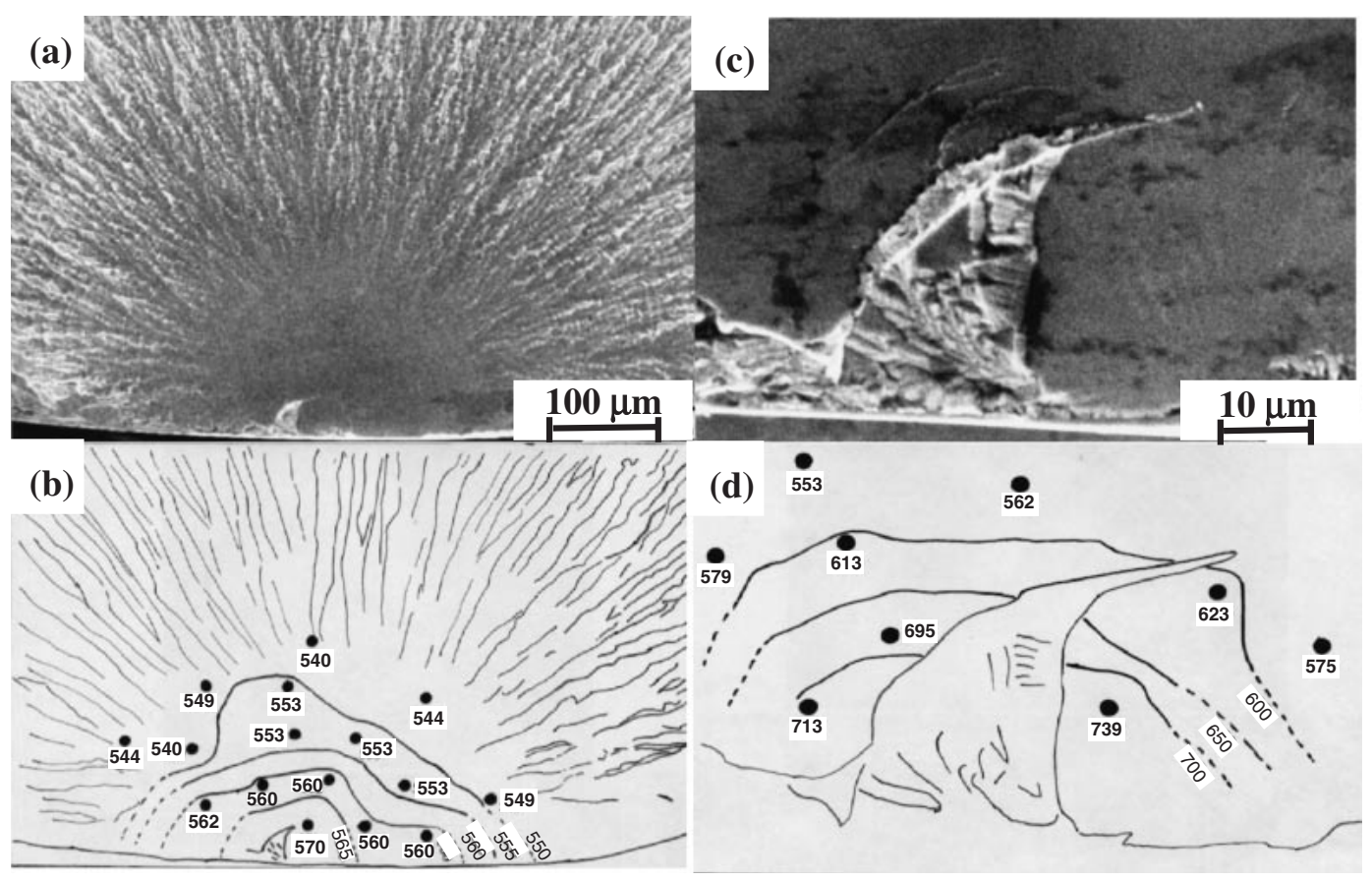

Fig. 3 SEM image of fatigue-fractured surface (a), its hardness distribution (b), magnified SEM image of crack initiation site (c) and its hardness distribution of $\mathrm{Pd}_{40} \mathrm{Cu}_{30} \mathrm{Ni}_{10} \mathrm{P}_{20}$ BGAs after fatigue testing $\left(\sigma_{\mathrm{a}}=240 \mathrm{MPa}\right.$ and $N_{\mathrm{f}}=3.3 \times 10^{8}$ cycles; arrow B), on Fig. 1$)$.

fractured regions. The maximum hardness was $720 \mathrm{HV}$, which cannot be achieved without crystallization. Nevertheless, we cannot observe any crystallization in the hardened area by TEM observation. Figure 3(a) depicts the fatiguefractured surface of $\mathrm{Pd}_{40} \mathrm{Cu}_{30} \mathrm{Ni}_{10} \mathrm{P}_{20}$ BGAs after fatigue testing $\left(\sigma_{\mathrm{a}}=240 \mathrm{MPa}\right.$ and $N_{\mathrm{f}}=3.3 \times 10^{8}$ cycles; arrow B in Fig. 1). There are no striation-like marks, and the fractured surface is similar to a typical oxide glass fractured surface with a mirror zone and a hackle zone. The hardness distribution in the mirror zone was hemi-cone-like and was maximized at the crack initiation site, as illustrated in Fig. 3(b). The fatigue fracture initiation site reveals an embrittled, fractured surface as chevron and river marks, as illustrated in Fig. 3(c). The hardness distribution around the fatigue fracture initiation site was also examined (Fig. 3(d)). The maximum hardness was $740 \mathrm{HV}$, which cannot be achieved even after crystallization by annealing. Nevertheless, we still could not observe any crystallized region in the hardening area by TEM observation. Consequently, the typical hardness distribution means that sufficient hardening in front of the crack tip effectively stops fatigue crack propagation. However, excessive hardening over $700 \mathrm{HV}$ might promote embrittlement in front of the fatigue crack tip during fatigue testing. Therefore, the stable fatigue crack propagation becomes unstable near the final fracture due to embrittlement. That is quite different from conventional crystalline engineering alloys.

To clarify the relationship between hydrogen concentration and hardness, we examined the hardness of electrode hydrogen absorbed $\mathrm{Zr}_{50} \mathrm{Cu}_{30} \mathrm{Ni}_{10} \mathrm{Al}_{10}$ BGAs (Fig. 4). There is no crystallization even after $15 \mathrm{~min}$, a long time for electrode hydrogen absorption. The relation between the

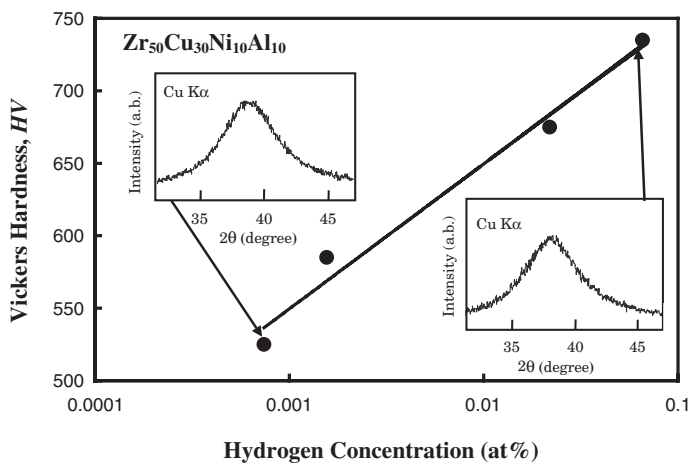

Fig. 4 Relationship between the Vickers hardness and hydrogen concentration of electrode hydrogen-charged $\mathrm{Zr}_{50} \mathrm{Cu}_{30} \mathrm{Ni}_{10} \mathrm{Al}_{10}$ BGAs and $\mathrm{X}$ ray diffraction patterns with different hydrogen concentrations.

hydrogen concentration and hardness is linear and exhibits a high Vickers hardness exceeding $700 \mathrm{HV}$ with 0.08 at $\%$ hydrogen while maintaining the glassy structure. However, since the hydrogen concentration was measured by the helium gas thermal conductivity method, the value of hydrogen concentration is not a net value of hardened region but an average value of bulk sample. The same relation is also seen in Pd-based BGAs (not shown). Accordingly, we can expect that the hardening in front of the fatigue crack is probably caused by the hydrogen concentration, which can stop the fatigue crack propagation just like the strain-aging effect.

In order to determine the hydrogen concentration on the hardened fatigue-fractured surface, we used nuclear reaction analysis to measure the hydrogen distribution in the depth 

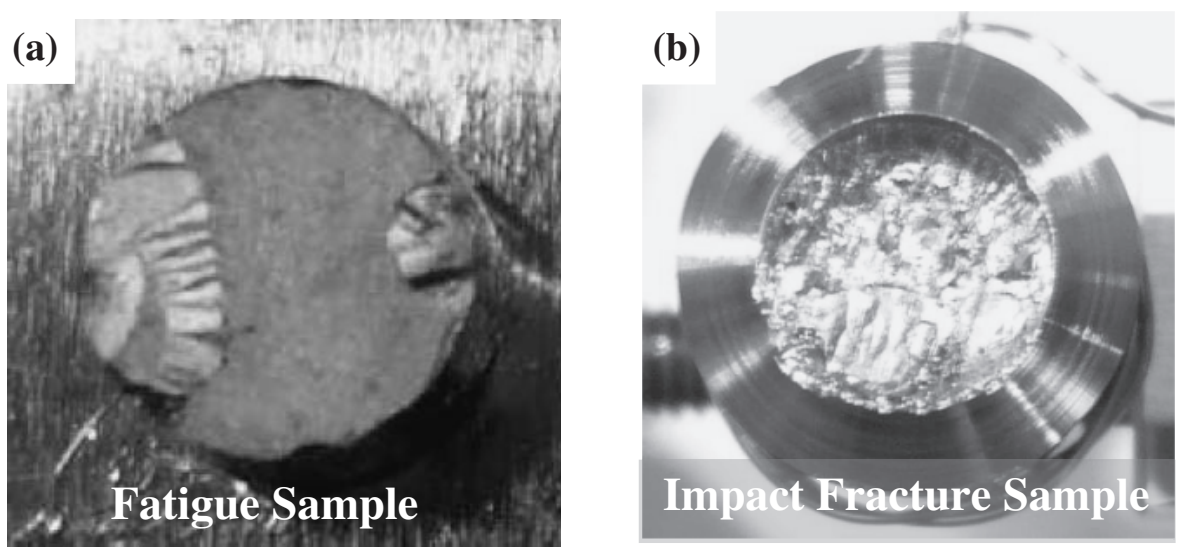

$2 \mathrm{~mm}$

(c)

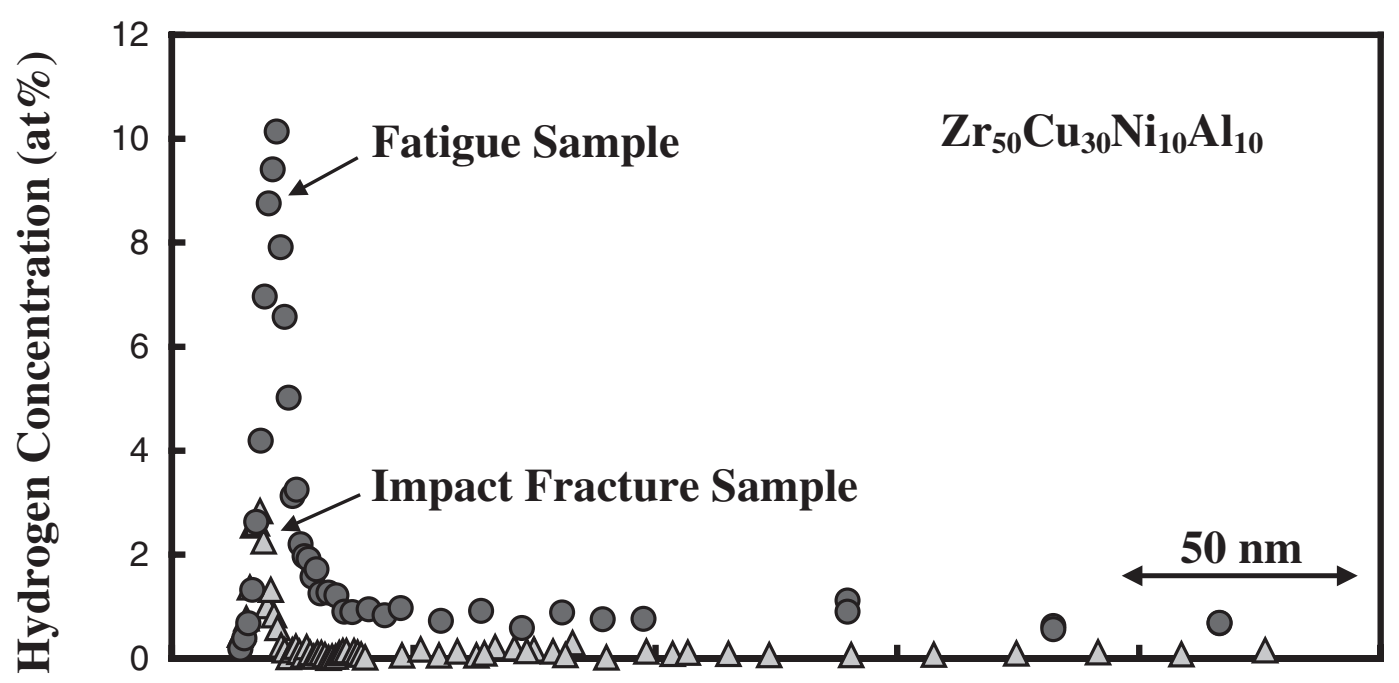

Depth from Surface

Fig. 5 OM images of fatigue-fractured $\left(\sigma_{\mathrm{a}}=760 \mathrm{MPa}\right.$ and $N_{\mathrm{f}}=1.7 \times 10^{4}$ cycles $)$ and impact-fractured $\mathrm{Zr}_{50} \mathrm{Cu}_{30} \mathrm{Ni}_{10} \mathrm{Al}_{10} \mathrm{BGAs}(\mathrm{a}$, b) and the hydrogen concentration distributions of the fatigue-fractured and impact-fractured $\mathrm{Zr}_{50} \mathrm{Cu}_{30} \mathrm{Ni}_{10} \mathrm{Al}_{10} \mathrm{BGAs}$ (c).

direction from the fatigue-fractured surface. Figure 5(a) and (b) present the fatigue-fractured $\left(\sigma_{\mathrm{a}}=760 \mathrm{MPa}\right.$ and $N_{\mathrm{f}}=$ $1.7 \times 10^{4}$ cycles) and impact fractured samples of $\mathrm{Zr}_{50^{-}}$ $\mathrm{Cu}_{30} \mathrm{Ni}_{10} \mathrm{Al}_{10}$ BGAs. Fatigue and impact fracture tests were performed in dry air at room temperature. Figure 5(c) plots the hydrogen distribution curves as a function of depth of the fatigue-fractured and impact-fractured $\mathrm{Zr}_{50} \mathrm{Cu}_{30} \mathrm{Ni}_{10} \mathrm{Al}_{10}$ BGAs. Fatigue-fractured sample exhibits a hydrogen-concentrated region up to 10 at $\%$ just under the surface, whereas the absolute value is quite different from the previous data because nuclear reaction analysis was applied measured in the local depth area. In contrast, the hydrogen distribution of the impact fractured sample is characterized by extremely low hydrogen concentration even just under the surface. Since the nuclear reaction analysis method cannot separate the hydrogen that absorbed on the surface, we have to exclude the hydrogen concentration profile near the surface about $10 \mathrm{~nm}$. We tried to remove the hydrogen concentration profile change by absorbed hydrogen that show the Gaussian profile near the surface. Even if it takes surface hydrogen adsorption into consideration, it can be said that the hydrogen concentration just under the fatigue fracture surface is very high. Furthermore, these hydrogen distribution curves of the fatigue fractured and impact fractured samples are quite different. The stress field around the fatigue crack tip probably condenses the hydrogen and then stabilizes into the deformed region. Since the incident beam diameter is about $5 \mathrm{~mm}$, the net hydrogen concentration of the hardened fatigue-fractured surface might be increased. Therefore, the localized stress field and yielding in front of fatigue crack tip effectively promote the hydrogen concentration during fatigue testing.

In order to obtain the BGAs with high fatigue strength, we have to control the hydrogen concentration around the fatigue crack tip to make the balance between promotion of sufficient hydrogen hardening for fatigue crack propagation stoppage 
and suppression of excessive hydrogen hardening for fatal embrittlement. Next step, we will perform in-situ measurement of the three-dimensional hydrogen distribution around the growing fatigue crack using a focused ${ }^{15} \mathrm{~N}$ ion beam $(6.385 \mathrm{MeV})$ to clarify the mechanism of stopping fatiguecrack propagation in detail. Consequently, we concluded that the significant hardening was caused by the hydrogen concentration around the fatigue crack tip and that it is an alternative to strain aging of ductile bulk glassy alloys.

\section{Summary}

The distributions of hardness and hydrogen concentration in $\mathrm{Zr}$ - and Pd-based BGAs were measured to determine the alternative strain-aging effect in ductile bulk glassy alloys. The results obtained are summarized below.

(1) The hardness of the fatigue-fractured Zr- and Pd-based BGAs is maximum just before the final fracture starts.

(2) An extremely high Hydrogen concentration was observed near the fatigue-fractured surface of $\mathrm{Zr}_{50} \mathrm{Cu}_{30} \mathrm{Ni}_{10} \mathrm{Al}_{10}$ BGA.

(3) Significant hardening, primarily caused by the hydrogen concentration around the fatigue crack tip, is considered as an alternative to the strain-aging effect of ductile Zr-based BGAs that interrupts the fatigue crack propagation.

\section{Acknowledgements}

This research is funded in part by the New Energy and Industrial Technology Development Organization (NEDO), and Grant-Aid for Science Research on Priority Area (Materials Science of Bulk Metallic Glasses) from the
Ministry of Education, Culture, Sports, Science and Technology.

\section{REFERENCES}

1) A. Inoue: Acta Mater. 48 (2000) 279-306.

2) A. Inoue: Intermetallics. 8 (2000) 455-468.

3) Y. Yokoyama, K. Yamano, K. Fukaura, H. Sunada and A. Inoue: Mater. Trans. 40 (1999) 1015-1018.

4) Y. Yokoyama, K. Yamano, K. Fukaura, H. Sunada and A. Inoue: Mater. Trans. 42 (2001) 623-632.

5) K. Fujita, A. Okamoto, N. Nishiyama, Y. Yokoyama, H. Kimura and A. Inoue: J. Alloys and Compounds (2007) in press.

6) Y. Yokoyama, K. Fukaura and H. Sunada: Mater. Trans. 41 (2000) 675-680.

7) K. Fujita, A. Inoue and T. Zhang: Mater. Trans. 41 (2000) 1448-1453.

8) W. H. Peter, P. K. Liaw, R. A. Buchanan, C. T. Liu, C. R. Brooks, J. A. Horton Jr., C. A. Carmichael Jr. and J. L. Wright: Intermetallics 10 (2002) 1125-1129.

9) A. L. Greer: J. Non-Cryst. Solids $61 \& 62$ (1984) 737-748.

10) Y. Yokoyama, Y. Akeno, T. Yamasaki, P. K. Liaw, R. A. Buchanan and A. Inoue: Mater. Trans. 46 (2006) 2755-2761.

11) A. Gebert, J. Eckert and L. Schultz: Acta Mater. 46 (1998) 5475-5482.

12) Y. Yokoyama, A. Kobayashi, K. Fukaura and A. Inoue: Mater. Trans. 43 (2002) 571-574.

13) Y. Yokoyama, T. Yamasaki, P. K. Liaw, R. A. Buchanan and A. Inoue: J. Alloys and Compounds (2007) in press.

14) Y. Yokoyama, P. K. Liaw, R. A. Buchanan and A. Inoue: Mater. Trans. 47 (2006) 1286-1293.

15) K. Fukutani: Current Opinion in Solid State \& Materials Science 6 (2002) 153-161.

16) Y. Yokoyama, K. Fukaura and A. Inoue: Mater. Trans. 45 (2004) 16721678.

17) Y. Yokoyama, N. Nishiyama, K. Fukaura, H. Sunada and A. Inoue: Mater. Trans. 42 (2001) 4301-4305.

18) K. Fukutani, M. Wilde, M. Matsumoto, Y. Murata and H. Yamashita: Solid State Physics 36 (2001) 353-358. 